\title{
Injury in rugby league: a four year prospective survey
}

\author{
Sarah Stephenson, Conor Gissane, Deanna Jennings
}

\begin{abstract}
Objective-To investigate the incidence of injury in English professional rugby league over a period of four playing seasons.

Methods-All injuries that were received by players during match play were recorded. Each injury was classified according to site, type, player position, team playing for, activity at the time of injury, and time off as a result of injury.

Results-The overall injury rate was 114 (95\% confidence interval 105 to 124$)$ per 1000 playing hours, the most frequent type of injury were muscular injuries [34 (29 to 40) per 1000 playing hours], while the most frequently injured site was the head and neck region [38 (16 to 25$)$ per 1000 playing hours]. Players received the largest percentage of injuries when being tackled [46.3\% (41.9 to 50.7)], most injuries required less than one week away from playing and training $[70.1 \%(66.1$ to 74.2$)]$, and forwards had a higher injury rate than backs (139 $v 93$ injuries per 1000 hours).

Conclusions-The high rates of injury in rugby league are undoubtedly due to the high amount of bodily contact in the game. Being tackled has the highest risk of injury, because of being hit forcibly by other players. Forwards suffer higher injury rates than backs, probably because they are involved in a larger number of physical collisions.
\end{abstract}

(Br F Sports Med 1996;30:331-334)

Department, West

Middlesex University

Hospital, Isleworth

Middlesex, United

Kingdom

S Stephenson,

physiotherapist

Department of Health

Studies, Brunel

University College,

Isleworth, Middlesex,

United Kingdom

C Gissane,

research officer

Reigate, Surrey,

United Kingdom

D Jennings, general

practitioner

Correspondence to:

C Gissane, Department of

Health Studies, Brunel

University College,

Isleworth, Middlesex TW7

$5 \mathrm{DU}$.

Accepted for publication

9 July 1996
Key terms: rugby league; injury; injury rate; prospective study

Rugby league is a physical game in which players are required to demonstrate speed, stamina, strength, and agility. ${ }^{1}$ It has been suggested that injury rates in rugby league are higher than in other main body contact sports such as rugby union, ${ }^{2-3}$ Australian rules football, and soccer. ${ }^{2}$ The possible reasons for the high injury rate are that players are involved in 20 to 40 physical "confrontations" per game, and that players wear minimal protective equipment, ${ }^{5}$ such as padding, which is designed to protect the soft tissues but not the bones and joints, ${ }^{6}$ or padded supports and sleeves for which, it has been suggested, there is no evidence of protection for injured muscles.?

However, it is acknowledged that research into many aspects of rugby league is extremely limited, ${ }^{8}$ not least on the incidence of injury. Previous investigations have reported on short time periods, ${ }^{39}$ and the only longitudinal investigations have been carried out in the Australian game. ${ }^{15}$ These studies also report widely differing findings, which could be due to the playing conditions, the skill level of players, the design of the studies, or the definition of what constitutes an injury. The purpose of this study was therefore to describe the incidence of injury in one professional rugby league club over a period of four seasons.

\section{Methods}

All injuries that were reported by players during the four seasons between July 1990 and May 1994 were recorded. A season ran from the beginning of preseason training to the last competitive match in either April or May. An injury was taken to be the onset of pain or a disability that occurred while playing rugby league football. ${ }^{3}$ The diagnosis and classification of injury was carried out by the club doctor and the physiotherapist. The site and injuries were categorised as described previously. ${ }^{9}$ The following details were recorded about each injury:

- The position of the player

- The site of the injury

- The nature of injury

- Whether the injury occurred in playing or training

- The team played for (first or " $\mathrm{A}$ " team)

- Activity at the time of injury

- Time off as a result of injury

The total number of games played during the four seasons was recorded. In total, there were 249 games played [first team 138, alliance ("A") team 111]. This included all competitions and friendlies. Playing hours at risk were calculated as the number of matches played $x$ 1.33 (each match lasting 80 minutes). Thirteen players in a side constitute 17.29 playing hours at risk during a game. Training sessions took place at the rate of two or three per week, involving approximately five hours work on game skills, with minimal body contact.

Statistical analysis consisted of the calculation of rates per 1000 hours of play and percentages; where appropriate rates were compared using the normal approximation as described by Clarke. ${ }^{10}$ Significance was set at the $\mathrm{P}<0.05$ level.

\section{Results}

During the four seasons under investigation, 599 medical conditions that prevented a player from either playing or taking part in club train- 
Table 1 Type of injury sustained in matches

\begin{tabular}{|c|c|c|c|c|c|c|c|c|c|}
\hline \multirow[b]{2}{*}{ Type of injury } & \multicolumn{3}{|c|}{ All players } & \multicolumn{3}{|l|}{ 1st Team } & \multicolumn{3}{|l|}{ A Team } \\
\hline & Number & $\begin{array}{l}\text { Rate per } \\
1000 \text { hours }\end{array}$ & $95 \% C I$ & Number & $\begin{array}{l}\text { Rate per } \\
1000 \text { hours }\end{array}$ & $95 \% C I$ & Number & $\begin{array}{l}\text { Rate per } \\
1000 \text { hours }\end{array}$ & $95 \% C I$ \\
\hline Haematomas & 68 & 16 & $12-20$ & 37 & 16 & $11-20$ & 32 & 17 & $11-22$ \\
\hline Muscle strains & 79 & 18 & $14-22$ & 51 & 21 & $29-44$ & 27 & 14 & $9-19$ \\
\hline Muscular injuries (total) & 147 & 34 & $29-40$ & 88 & 37 & $25-37$ & 59 & 31 & $23-39$ \\
\hline Joint sprain & 117 & 27 & $22-32$ & 61 & 26 & $16-27$ & 56 & 29 & $22-37$ \\
\hline Laceration & 85 & 20 & $16-24$ & 66 & 28 & $21-34$ & 19 & 10 & 6-14 \\
\hline Contusion & 51 & 12 & $9-15$ & 28 & 12 & $7-16$ & 23 & 12 & $7-17$ \\
\hline Fracture and dislocation & 40 & 9 & $6-12$ & 25 & 10 & $6-15$ & 15 & 8 & $4-12$ \\
\hline Concussion & 35 & 8 & $6-11$ & 18 & 8 & $4-11$ & 17 & 9 & $5-13$ \\
\hline Abrasion and skin infection & 10 & 2 & $1-4$ & 7 & 3 & $1-5$ & 3 & 2 & $1-5$ \\
\hline Others & 7 & 2 & $1-3$ & 4 & 2 & $1-4$ & 3 & 2 & $1-5$ \\
\hline All types & 492 & 114 & $105-124$ & 297 & 124 & $111-138$ & 195 & 102 & $88-115$ \\
\hline
\end{tabular}

CI, confidence interval.

Table 2 Site of injury sustained in matches

\begin{tabular}{|c|c|c|c|c|c|c|c|c|c|}
\hline \multirow[b]{2}{*}{ Site of injury } & \multicolumn{3}{|c|}{ All players } & \multicolumn{3}{|l|}{ 1st Team } & \multicolumn{3}{|l|}{ A Team } \\
\hline & Number & $\begin{array}{l}\text { Rate per } \\
1000 \text { hours }\end{array}$ & $95 \% C I$ & Number & $\begin{array}{l}\text { Rate per } \\
1000 \text { hours }\end{array}$ & $95 \% C I$ & Number & $\begin{array}{l}\text { Rate per } \\
1000 \text { hours }\end{array}$ & $95 \% C I$ \\
\hline Head and neck & 165 & 38 & $33-44$ & 111 & 47 & $38-55$ & 54 & 28 & $21-36$ \\
\hline Thigh and calf & 88 & 20 & $16-25$ & 49 & 21 & $15-26$ & 39 & 20 & $14-27$ \\
\hline Knee & 50 & 12 & $8-15$ & 28 & 12 & $7-16$ & 22 & 11 & $7-16$ \\
\hline Thorax and abdomen & 45 & 10 & $7-14$ & 24 & 10 & $6-14$ & 21 & 11 & $6-16$ \\
\hline Shoulder & 41 & 10 & $7-12$ & 26 & 11 & $7-15$ & 15 & 8 & $4-12$ \\
\hline Ankle & 40 & 9 & $6-12$ & 24 & 10 & $6-14$ & 16 & 8 & $4-12$ \\
\hline Arm & 32 & 7 & $5-10$ & 19 & 8 & $4-12$ & 13 & 7 & $3-10$ \\
\hline Others & 31 & 7 & $5-10$ & 16 & 7 & $3-10$ & 15 & 8 & $4-12$ \\
\hline All sites & 492 & 114 & $105-124$ & 297 & 124 & $111-138$ & 195 & 102 & $88-115$ \\
\hline
\end{tabular}

CI, confidence interval.

Table 3 Activity at the time of being injured

\begin{tabular}{|c|c|c|c|c|c|c|c|c|c|}
\hline \multirow[b]{2}{*}{ Activity } & \multicolumn{3}{|c|}{ All players } & \multicolumn{3}{|l|}{ 1st Team } & \multicolumn{3}{|l|}{ A Team } \\
\hline & Number & $\begin{array}{l}\text { Rate per } \\
1000 \text { hours }\end{array}$ & $95 \% C I$ & Number & $\begin{array}{l}\text { Rate per } \\
1000 \text { hours }\end{array}$ & $95 \% C I$ & Number & $\begin{array}{l}\text { Rate per } \\
1000 \text { hours }\end{array}$ & $95 \% C I$ \\
\hline Tackled & 228 & 46.3 & $41.9-50.7$ & 138 & 46.5 & $40.8-52.1$ & 90 & 46.2 & $38.2-53.2$ \\
\hline Other & 159 & 32.3 & $28.2-36.4$ & 99 & 33.3 & $28.0-38.7$ & 60 & 30.8 & $24.3-37.2$ \\
\hline Tackler & 105 & 21.3 & $17.7-25.0$ & 60 & 20.2 & $15.6-24.8$ & 45 & 23.1 & $17.2-29.0$ \\
\hline Total & 492 & 100.0 & $99.3-100$ & 297 & 100.0 & $98.8-100$ & 195 & 100.0 & $98.1-100$ \\
\hline
\end{tabular}

CI, confidence interval.

ing for rugby league were recorded. Of these, 27 were illnesses and conditions such as sickness, and were excluded from the analysis. This left a total of 572 sports injuries, 492 $(82.1 \%)$ of which were received during match play and $80(13.9 \%)$ during training.

Of the 492 match injuries, 297 (60.4\%) were to first team players and $195(39.6 \%)$ to A team players. This equates to an overall incidence rate of 114 injuries per 1000 hours of match play (first team, 124; $\mathrm{A}$ team, 102; $\mathrm{z}=$ $2.2, \mathrm{P}<0.05$ ).

The types of injuries sustained during match play are shown in table 1 . The highest injury rates were for muscular injuries (haematomas and strains) ( 34 per 1000 hours). When examining the first and A teams separately, the same type of injury was the most common (first team 37, A team 31 per 1000 hours; $z=4.7, P<$ $0.05)$. The types of injury that were least common were abrasions and skin infections and "others" (both 2 per 1000 hours).

The sites of injuries sustained by players are shown in table 2 , which indicated that the region of the body that suffers the highest injury rates is the head and neck (38 per 1000 hours). The same site was also the most injured when comparing the first and A teams, although the two rates are markedly different (47 $v 28$ per 1000 hours; first team $v$ A team; $\mathrm{z}$ $=3.2, \mathrm{P}<0.05)$. The next most commonly injured site in the body was the thigh and calf, but the injury rate was less than half that of the head and neck ( 20 per 1000 hours). The least injured sites of the body were the arm and the "others" category, which included such areas as fingers and toes (both 7 per 1000 hours).

The figures for the first and A teams are given in table 3 and tended to be quite similar. Of all the playing injuries the largest percentage was received when a player was being tackled $(46.3 \%)$, while a tackler was injured in $21.3 \%$ of the injury events. The remaining $32.3 \%$ were classified as "others", which included injuries during such activities as running and scrummaging.

The amount of time off taken by players as a result of injury is shown in table 4 . It can be seen that more than two thirds of all injuries sustained required a player to take less than one week away from playing and training, a relatively small proportion of injuries $(7.5 \%)$ required a player to be away from training for more than four weeks. 
Table 4 Time off as a result of being injured

\begin{tabular}{|c|c|c|c|c|c|c|c|c|c|}
\hline \multirow[b]{2}{*}{ Time off } & \multicolumn{3}{|c|}{ All players } & \multicolumn{3}{|l|}{ 1st Team } & \multicolumn{3}{|l|}{$A$ Team } \\
\hline & Number & $\begin{array}{l}\text { Rate per } \\
1000 \text { hours }\end{array}$ & $95 \% C I$ & Number & $\begin{array}{l}\text { Rate per } \\
1000 \text { hours }\end{array}$ & $95 \% C I$ & Number & $\begin{array}{l}\text { Rate per } \\
1000 \text { hours }\end{array}$ & $95 \% C I$ \\
\hline $1-2$ weeks & 67 & 13.6 & $10.6-16.6$ & 32 & 10.8 & $7.3-14.3$ & 35 & 17.9 & $12.6-23.3$ \\
\hline 2-3 weeks & 32 & 6.5 & $4.3-8.7$ & 14 & 4.7 & $2.3-7.1$ & 18 & 9.2 & $5.2-13.3$ \\
\hline 3-4 weeks & 11 & 2.2 & $0.9-3.5$ & 5 & 1.7 & $0.6-3.9$ & 6 & 3.1 & $0.6-5.5$ \\
\hline$>4$ weeks & 37 & 7.5 & $5.2-9.6$ & 21 & 7.1 & $4.2-10.0$ & 16 & 8.2 & $4.4-12.1$ \\
\hline Total & 492 & 100.0 & $99.3-100$ & 297 & 100.0 & $98.8-100$ & 195 & 100.0 & $98.1-100$ \\
\hline
\end{tabular}

CI, confidence interval.

Table 5 Distribution of injury between forwards and backs

\begin{tabular}{|c|c|c|c|c|c|c|c|c|c|}
\hline \multirow[b]{2}{*}{ Position } & \multicolumn{3}{|c|}{ All players } & \multicolumn{3}{|l|}{ 1st Team } & \multicolumn{3}{|l|}{ A Team } \\
\hline & Number & $\begin{array}{l}\text { Rate per } \\
1000 \text { hours }\end{array}$ & $95 \% C I$ & Number & $\begin{array}{l}\text { Rate per } \\
1000 \text { hours }\end{array}$ & $95 \% C I$ & Number & $\begin{array}{l}\text { Rate per } \\
1000 \text { hours }\end{array}$ & $95 \% C I$ \\
\hline Forwards & 277 & 139 & $124-155$ & 169 & 153 & $113-150$ & 108 & 122 & $100-144$ \\
\hline Backs & 215 & 93 & 81-105 & 128 & 100 & 83-116 & 87 & 84 & $67-101$ \\
\hline Total & 492 & 114 & $105-124$ & 297 & 124 & $111-138$ & 195 & 102 & $88-115$ \\
\hline
\end{tabular}

CI, confidence interval.

Table 6 Classification of concussions

\begin{tabular}{ll}
\hline Severity of concussion & Action \\
\hline $\begin{array}{l}\text { Mild: no loss of consciousness (LOC) } \\
\text { i. Full memory of event }\end{array}$ & $\begin{array}{l}\text { Can usually continue playing (after being checked) } \\
\text { ii. Memory deficit of event }\end{array}$ \\
$\begin{array}{l}\text { Moderate: (LOC) of up to } 2 \text { minutes } \\
\text { Severe: }\end{array}$ & $\begin{array}{l}\text { Must cease playing: no playing or training for } 15 \text { days and only after a medical check by the club doctor } \\
\text { i. LOC of up to } 3 \text { minutes }\end{array}$ \\
$\begin{array}{l}\text { Must cease playing: no playing or training for } 22 \text { days and only after a medical check by the club doctor } \\
\text { Must cease playing: and be admitted to hospital for observation: no playing or training for } 29 \text { days and only after }\end{array}$
\end{tabular}

All cases of SEVERE concussion should have $x$ rays of the skull and cervical spine.

Source: The Rugby Football League (1993).

The incidence of injury for forwards and backs is shown in table 5 . From this it can be seen that forwards are injured more frequently than backs in absolute terms (56.3 $v 43.7 \%$, both first and A teams). When the rate is standardised for the number of players (six forwards and seven backs), the injury rate differences are even larger (forwards $139 v$ backs 93 per 1000 hours; $z=4.5, P<0.05$ ).

\section{Discussion}

In this study we found an overall injury incidence rate in rugby league of 114 injuries per 1000 man hours of play. It has been suggested that the high injury rate is due to repeated hard body contact. ${ }^{5}$ The injury rate in the current study is higher than the rate of 14 that has been reported for rugby union, ${ }^{11}$ and also higher than the rate of 45 per 1000 hours that has been reported for Australian rugby league. ${ }^{1}$ One probable reason for the differing rates between Australian and English rugby league, and League and Union was the decision of previous studies ${ }^{111}$ only to include injuries that required a player to miss a subsequent game, the games being played on a weekly basis. If in the present study injuries requiring less than one week to recover from are excluded the overall rate is reduced to 34 per 1000 hours (first team 30, A team 39 per 1000 hours). However, this may not strictly be comparable, as situations such as weather conditions in England may result in more than a week between games. Then postponed games, which must be played later in the season, could result in a fixture backlog requiring more than one game to be played per week.

Muscular injuries accounted for $29.9 \%$ of all injury types. This is similar to values that have previously been reported. ${ }^{1213}$ Injuries of this type to the quadriceps have been reported to be common as this is the first point of contact in the tackle. ${ }^{5}$ It could be argued that a game which has been likened to being mugged 30 times in 80 minutes, ${ }^{14}$ which involves a player in 20 to 40 physical "confrontations" per game, ${ }^{4}$ predisposes players to this type of injury.

The site of the body to which most injuries took place was the head and neck region, with $33.3 \%$ of all injuries. This is higher than has been previously reported, with studies quoting values ranging from $5.8 \%^{1}$ to $28.8 \%{ }^{9}$ of all injuries. Again, the decision to include minor injuries may account for part of the difference. But at least one other study chose to include minor injuries, ${ }^{17}$ and commented that head and neck injuries were on the increase. While another reported that head lacerations were very common, although they did not require players to miss games.

The observation that a majority of injuries are caused in the tackle is common to both rugby codes. ${ }^{3111^{15}-17}$ The findings of the present study show that the player being tackled is more likely to be injured (46.3\%), and this is also in agreement with previous research. ${ }^{317}$ In rugby league, the tackle is a very prominent part of the game, which carries inherent dangers such as being knocked over backwards, whiplash, and the clashing of heads. ${ }^{4}$ 
This study also reported that $32.3 \%$ of players were injured in situations classified as "others"; this must be considered a limitation of the study. With almost one third of injuries falling into this category, it is clear that it is too large as a general classification, and that future research should attempt to break this down into more component parts. For example, some injuries may have occurred as a result of foul play but were not recorded as such. Nevertheless, the sport is concerned about such incidents, and this was emphasised by the Rugby League issuing a directive in January 1995 specifically making lifting a player and "spear tackling" him a sending off offence under Law 15.1d regarding illegal throws.

The vast majority of injuries recorded in this study $(70.1 \%)$ required that a player be absent from training and playing for less than a week. Part of the reason for this high figure was the decision to include all injures received while playing. Gibbs, ${ }^{1}$ who defined an injury as an event that required a player to miss the next week's game, reported that the largest proportion $(38 \%)$ of injuries required players to miss the next game. If the injuries requiring less than one week off play are excluded from the current analysis, the largest proportion required one to two weeks absence $(46 \%)$. However, classifying injuries in this way can be shown to miss many minor injuries. ${ }^{18}$ Also, it should be pointed out that $17 \%$ of the injuries recorded in this study were lacerations. The majority of these would have involved the "blood-bin", which began in the 1991-2 season after concern over such injuries. Furthermore, one investigation reported that such injuries rarely cause a player to miss a game, but counted 101 over five seasons. ${ }^{5}$ If they were counted, they would add considerably to both the numbers of, and the injury rates.

A possible explanation for differences between the League and Union codes might be the specific regulations regarding concussions. The International Rugby Football Board resolution (5.7) requires a concussed player to refrain from playing and training for a period of at least three weeks after the injury, and subject to being cleared by a proper examination. ${ }^{7}$ However, in rugby league, concussion is graded by severity, as shown in table 6 . This could result in injuries being recorded but players requiring less time away from playing and training.

The finding that backs are injured much more frequently than forwards has been observed by others. ${ }^{1211}$ It has also been reported that forwards received a larger than expected number of injuries, based on the number of player positions. ${ }^{1}$ As backs run the ball more and forwards tend to be involved in more collisions, ${ }^{4}$ then perhaps they should be more susceptible to injuries. It has also been suggested that the pattern of injury between forwards and backs might change with an alteration in the style of play. ${ }^{11}$

The results from our study show that rugby league has very high injury rates. This is undoubtedly due to the large amount of physi- cal body contact between players. Injury rates were shown to be higher at the highest standards of play. Forwards experience greater rates of injury than backs, which is probably due to their being involved in more repetitive body contact than backs. Perhaps future research should examine the differing injury rates between forwards and backs in relation to their game-specific work loads, and also analyse what types of injury these respective groups receive during the course of a game.

We would like to thank Dr J A White, Dr L Rushton, Dr J C G Pearson, and Ms C A C Coupland for their assistance while writing this paper.

\section{Postscript}

During the peer review of this paper, the reviewers made some extremely useful and helpful comments. For some of these points, we had the necessary information available and could address the issues, while unfortunately for others we could not do so.

One of these points was related to information on the incidence of foul play, which was not collected. The reason for this was that when the register was begun back in 1990, we collected what we thought was relevant at the time. At that time, there were almost no studies available on rugby league and an overall picture of the injury situation was needed. This is not to say that foul play is not an extremely important issue, but with the advent of the Super League concern has shifted. The Rugby League Medical Association is currently more concerned with the effect that playing on hard ground will have on overall injury rates and with the potential for heat stress injuries.

1 Gibbs N. Injuries in professional rugby league: a three year prospective study of the South Sydney professional rugby

2 Seward $\mathrm{H}$, Orchard J, Hazard $\mathrm{H}$. Football injuries in Australia at the elite level. Med $\mathcal{F}$ Aust 1993;159:298-306. rugby league football. Physiotherapy 1993;79:305-10.

rugby league football. Physiotherapy 1993;79:305-10.
4 Larder P. The rugby league coaching manual, 2nd ed. London: Kingswood Press, 1992.

5 Gibbs N. Common rugby league injuries: recommendations for treatment and preventative measures. Sports Med 1994; 18:438-50.

6 Dornan P Dunn R. Sporting injuries. London: University of Queensland Press, 1987.

7 MacLeod DAD. Risks and injuries in rugby football. In: McLatchie GR, Lennox CME, eds. The soft tissues: trauma and sports injuries. Oxford: ButterworthHeinnemann, 1993:371-81.

8 Brewer J, Davies J. Applied physiology of rugby league. Sports Med 1995;20:129-35.

9 Alexander D, Kennedy M, Kennedy J. Rugby league football injuries over competitive two seasons Med $\mathcal{F}$ Aust 1980;2:334-5.

10 Clarke GM. Statistics and experimental design: an introduction for biologists and biochemists. London: Edward Arnold, 1994. 1 Garroway M, Macleod D. Epidemiology of rugby football injuries. Lancet 1995;345:1485-7.

injuries. Lancet 1995;345:1485-7.
Alexander D, Kennedy M, Kennedy J. Injuries in rugby league football, Med $\mathcal{F}$ Aust 1979;2:341--2.

13 Walker RD. Sports injuries: rugby league maybe less dangerous than union. Practitioner 1985;229:205--6.

14 O'Hare M. In a league of their own. New Scientist 1995;1997:30-5.

5 Addley K, Farren J. Irish rugby injury survey: Dungannon football club (1986-1987). Br f Sports Med 1988;22:22-4. 16 Inglis GS, Stewart ID. Rugby injury survey 1979. NZ Med f 1981;11:349-50.

17 Lythe MA, Norton RN. Rugby League injuries in New Zealand. NZ F Sports Med 1992;20:6-7.

18 Inklaar H. Soccer injuries I: incidence and severity. Sports Med 1994;18:55- 73. 